\title{
A Generic Concept for Reducing Complexity in International Operations - An Asymptotic Strive for Manufacturing Simplicity
}

\author{
Martin Rudberg, Martin West and Jan Olhager \\ Department of Production Economics \\ Linköping Institute of Technology, S-581 83 Linköping, Sweden \\ +4613281000 (tel.), +4613288975 (fax) \\ jan.olhager@ipe.liu.se
}

\begin{abstract}
In this paper, we introduce and discuss a generic concept that systematically enables a reduction of strategic and operational complexity for manufacturing firms operating in international markets. The discussion is based on a live case, where the objective is to reach maximum simplicity in global manufacturing operations with respect to both product and process design.
\end{abstract}

\section{Keywords}

Global manufacturing, manufacturing strategy, agile manufacturing, flexibility, manufacturing planning and control 


\section{INTRODUCTION}

Industrial firms are in many ways becoming more and more international. They face fierce competition globally, and as a response they globalize their manufacturing operations, the overall purpose being to achieve the best network of manufacturing and supply facilities relative the marketplace, see e.g. Boone et. al. (1996), and Davidsson and de la Torre (1989). This is especially the case for standardized high-volume products serving the global market, for instance the three time zones - the triad - formed by the USA, Europe and Asia, see e.g. Ohmae (1985), and Rugman and Verbeke (1990). Then, a global manufacturing strategy is needed for coordination of these activities. A typical ingredient in such a strategy is a standardization of procedures and systems, in order to facilitate a global control. One such model, called the Model Factory Concept, is described by the authors in a previous paper (Rudberg et. al., 1998). In the Model Factory Concept, the global manufacturing network is arranged in master and clone (copy) function responsibilities. These responsibilities are linked to different products, meaning that a factory can have both master and clone responsibilities. There is, however, only one master function for each product, but there can be many clone functions. Knowledge and developments are continuously transferred between factories. New products are always introduced at an existing or projected factory with master function responsibilities, hence working as an advanced pilot plant. When the production process is stable, it can be transferred to other factories that thereby get clone function responsibilities for the product. Ericsson Radio Systems $\mathrm{AB}$, manufacturing and marketing base stations for mobile communications have employed this model for a few years. Ericsson's operations are global - products are standardized, product volumes are high as well as the overall growth rate and the rate of new product introductions. Furthermore, product life cycles are short. Therefore, a global manufacturing strategy is of utmost importance.

However, it has proven to be difficult to maintain a low level of complexity when dealing with ever-increasing international activities. More often, a successively higher degree of complexity is induced in the strategic management of the manufacturing value network, see e.g. Hamel and Prahalad (1985), and Boone et. al. (1996). Several multinational companies even try to decipher the network complexity by implementing more advanced manufacturing strategies and information systems. The Ericsson approach is quite different. In order not to increase complexity, they are currently working with a new concept, called the Asymptote Concept. The purpose of this concept is to develop guidelines for manufacturing operations that will ascertain a move towards simplicity in both product and process design.

In this paper, we present the Asymptote Concept and provide analyses from various perspectives. This approach is currently under way in three pilot cases and a broader implementation is expected in the near future. First, we evaluate the Asymptote Concept from a general manufacturing strategy point of view, also including manufacturing planning and control issues. Then, we deal with issues related to flexibility and economies of scale. 


\section{DESCRIPTION OF THE ASYMPTOTE CONCEPT}

To reverse the trend of increasing complexity in the production system, Ericsson has developed operational guidelines in a concept that focuses on simplicity. Based on a minimal case - a virtual product - Ericsson has defined goals for a number of parameters, e.g. inventory turnover, lead-time, quality etc. As these goals are difficult to achieve with the current set of products and production systems, product design is entirely focused on minimizing complexity in the product. This is in turn a prerequisite for designing very simple and agile production processes. Concerning the nature of today's product and technology, it is impossible to approach the minimal case in only one product revision - it will take several revisions, possibly dependent of new technology. For every reengineering opportunity linked to a product revision, a minimum amount of supporting activities are added to the asymptote factory - activities that are not possible to eliminate at that point in time and with the current technology. Thus, taking the asymptote factory perspective, the production system is designed according to bottom-up reengineering rather than top-down continuous improvement, as illustrated in Figure 1.

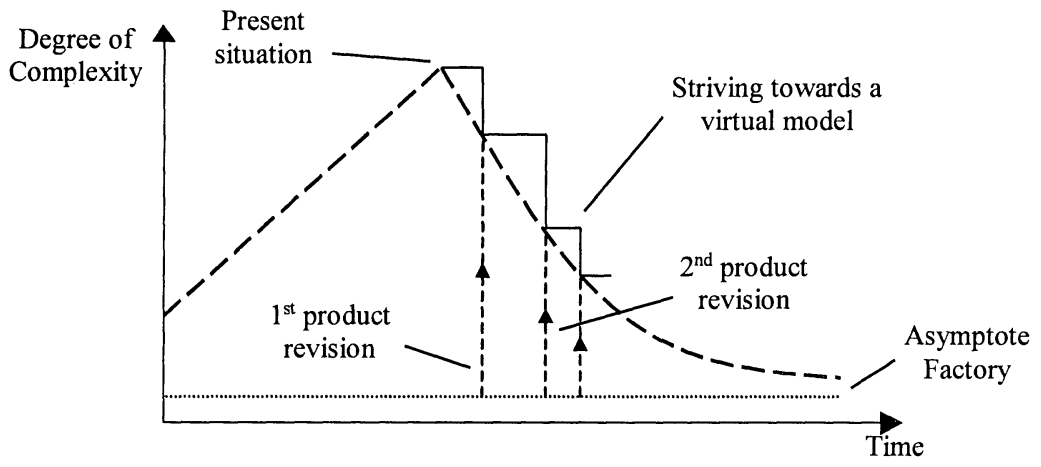

Figure 1 Striving for an asymptote in manufacturing simplicity.

The concept of moving towards the simplest form of production system possible has been coined the Asymptote Concept (AC) by Ericsson. The concept is a continuation and further development of an abstraction of how plants are to be designed and operated in a global market, labeled the Model Factory Concept (MFC) that has shown to accompany some drawbacks. With the AC, these drawbacks are addressed and the correcting measures are amended to the MFC. Below we describe how the $\mathrm{AC}$ is used to create simplicity in the manufacturing processes and control systems, accomplished by having clear strategies for capacity changes, supplier interface, organization, and manufacturing planning and control (MPC).

The capacity is treated in blocks, in so-called micro factories. A micro factory is a well-defined production process regarding layout, product mix and volumes, organization, and supplier structure. A macro factory is then made up of a set of 
micro factories. Finally, plants can consist of a number of macro factories. This relationship resembles the plants-within-a-plant concept (see e.g. Hayes and Wheelwright, 1984).

The micro factories are designed to produce complete products, and every micro factory is arranged to produce most, if not all products within a product family. To support this production arrangement the organization has a clear and distinct product focus, where a production team is responsible for the complete manufacturing value chain, from order initiation to packaging. The team is also responsible for the call-off of material and follow-up activities to assure customer satisfaction. The production team is in turn supported by functional departments, e.g. technical support, quality assurance etc, located on the shop floor near the physical flows. These functions typically support all micro factories within a macro factory, but could be specific for only one micro factory.

To enable a simple material replenishment system with call-off, it is necessary to work in close relationship with a few suppliers. Ericsson has chosen to distinguish between crucial and non-crucial components. The control of crucial components is usually managed at the macro level, with the suppliers closely tied to the enterprise, whilst non-crucial components are managed at the micro level, gathered and delivered to the plant by one single distributor. Thereby, the supplier interface is easily managed, and the suppliers can be treated differently depending upon their capabilities. In the ideal case, replenishment of all material is made via EDI (Electronic Data Interchange) or Internet, with a 24-hour lead-time. The close relationship with suppliers is also a prerequisite for short lead-times. Instead of purchasing a prespecified amount of components, Ericsson has now turned to securing capacity at its suppliers. The amount of components delivered to Ericsson is decided upon by Ericsson a few days prior to delivery, but in accordance with the reserved capacity.

The structure of the MPC system in the $\mathrm{AC}$ is set up according to the prerequisite of the minimal case (see Figure 2). The MPC is divided into two flows: the socalled forecast and time-to-customer (TTC) flows. Connected to these flows is the time-to-market (TTM) flow, featuring new product introduction and product revisions. In the forecast flow, the business unit collects forecasts from the three time zones in the global supply planning, where sales and production plans are assigned to the plants in the global network. At the plant level, requirements planning is carried out with respect to the results of the global supply plan. Besides the traditional sales and operations planning (S\&OP) and resource planning, Ericsson involves their suppliers in the planning by securing capacity according to the S\&OP. The requirements planning also includes continual delivery of forecasts and trends to suppliers, as well as monitoring capacity at supplier bottlenecks.

The production planning is carried out at the macro factory level, where a master production schedule (MPS) is set consistent and taking into account the S\&OP, the secured capacity in-house and at the suppliers and distributors. The MPS is used in the order management, where orders are configured and confirmed, and delivery promises are made. 


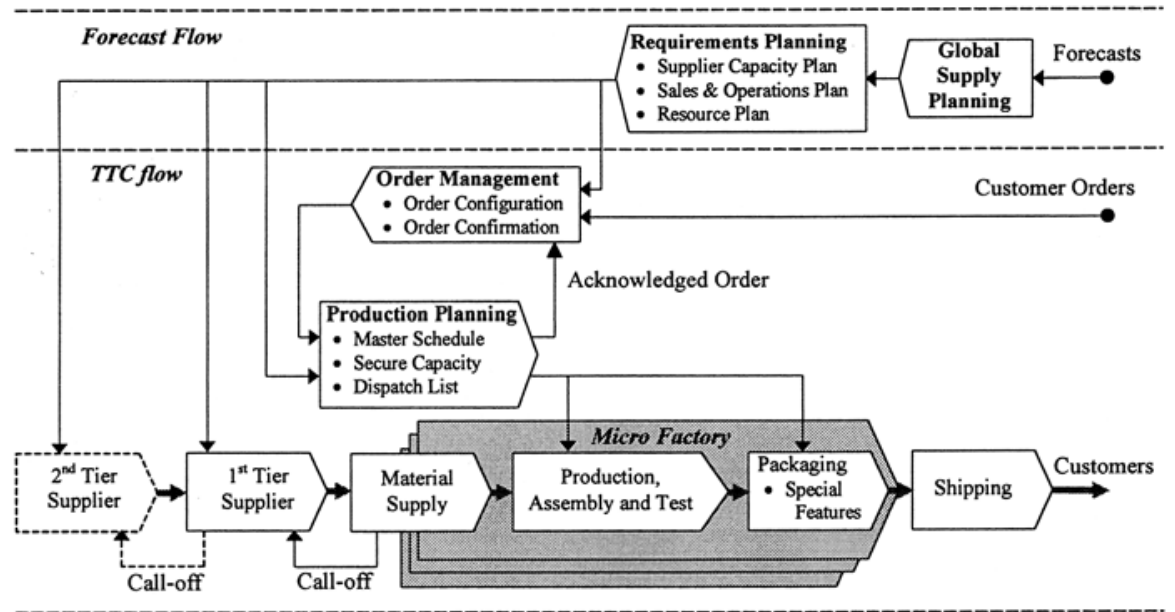

Figure 2 The structure of the MPC system in the AC.

A demand time fence is used where a frozen schedule is set for the next day only. When orders are acknowledged and scheduled, dispatch lists and pick lists are released to the respective micro factory. The bill-of-material is used only to identify crucial components and customer specific requirements for purchasing and manufacturing, and to specify the pick list.

Thus, the AC strives for customer order-driven production, based on extremely short lead-times and a simple and visible product flow, where the order penetration point moves further up the product flow with every product revision. Less complex operations reduces the need for complex tools, techniques and systems, and facilitates a transition to reduced lead-times - a prerequisite for improved delivery precision and inventory turnover.

\section{MANUFACTURING STRATEGY, PLANNING AND CONTROL ISSUES}

Even though a global competitor must view its international activities as an overall system, it still has to maintain some country perspective, according to Porter (1986). He furthermore states that the balancing of these two perspectives is one of the essential questions in a global strategy. Ericsson's answer is the MFC, which creates what could be called a "local globalization" (see Rudberg et. al., 1998). Porter (1986) uses a matrix, shown in Figure 3, to classify enterprises working on a global basis, where the two key dimensions are the configuration of a firm's worldwide activities, and the coordination of these activities. It seems like global companies nowadays are moving towards the upper left-hand corner, since concentration is less possible and coordination thereby is more important in today's competitive global environment. 


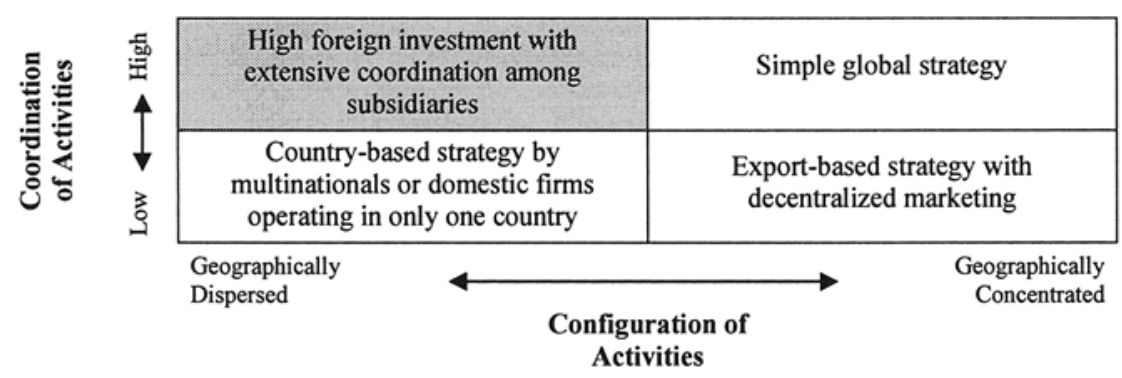

Figure 3 Types of international strategy. The shaded area indicates Ericsson's position. (Source: Porter, 1986.)

Ericsson, with its tightly coordinated manufacturing strategy (employing the same information system, the same production process, specifications, and so forth) is already there. The shift to a truly global strategy has, however, resulted in two new major problems for Ericsson. Firstly, the need of coordination has generated requirements on more advanced and thereby complex tools to control the global manufacturing activities. Secondly, global competition combined with a transfer from the introduction-growth phase to the growth-maturity phase in the product life cycle of radio base stations, has led to a change of orderwinning characteristics (see e.g. Hill, 1995). The AC is developed to overcome these problems. By stressing simplicity in product design, the processes can be simplified accordingly, whereby the use of advanced planning and control systems can be minimized. The MPC procedure is based on gross requirements planning with secured capacity both in-house and at suppliers, using a call-off system with very short lead-times. To a large extent, the AC facilitates the elimination of detailed material planning, which in Vollmann et. al. (1997) is called the "engine" of the MPC system, and computerized MPC systems.

From supporting the former orderwinners (innovativeness, performance, and flexibility), with a combination of a batch flow and an operator-paced line flow system, Ericsson now has to change to support the new orderwinners: delivery (speed and reliability) and cost (cf. Miltenburg (1995) regarding how different process choices support different orderwinning characteristics). The AC also includes features to manage this change, solving the second problem, by using a higher degree of automation, especially in the most difficult steps in the production process, and a more flow and product oriented process. This results in a more equipment-paced line flow type system, also more suitable for today's more standardized products and higher volumes in the telecommunication business.

\section{ECONOMIES OF SCALE AND FLEXIBILITY ISSUES}

The MFC updated with the $\mathrm{AC}$ will form a formidable competitive weapon regarding the firms market flexibility, defined as the ease with which the manufacturing system can adapt to a changing market environment (Sethi and Sethi, 1990). Market flexibility is made up of three types of flexibility, viz. 
product, volume and expansion flexibility, all inherent characteristics in the $\mathrm{MFC} / \mathrm{AC}$.

Product flexibility is the ease with which new parts can be added or substituted for existing parts (Sethi and Sethi, 1990). This kind of flexibility is obtained by the AC primarily through the design of the products, which are developed for minimum complexity and based on modularity. It is also notable that components should, as far as possible, be the same for different products.

Volume flexibility is defined as the ability of the manufacturing system to operate profitably at different output levels (Sethi and Sethi, 1990). Ericsson attains this by the highly automated micro factories, allowed to produce without a large labor force that is hard and costly to adjust both upwards and downwards. However, Ericsson has also made arrangements with different labor pools for short-term contracting of personnel. In addition, the labor force is flexible in competence - hence it can be used elsewhere when produced volumes decline.

Expansion flexibility, defined as the ease with which the capacity and capability of the manufacturing system can be increased when needed (Sethi and Sethi, 1990), is obtained as the use of micro factories in the MFC/AC facilitates an easy enhancement of capacity. The high level of automation of the micro factories makes it smooth to add additional shifts when needed. The standardized policies for transfer and ramp-up of production in the MFC facilitate a fast and easy set up of a new micro factory. Since no complex tools are needed to support and control the manufacturing process, the shift in capacity does not require any major design change of the MPC system.

When a plant and the accompanying organization grow large, it is a common belief that economies of scale are eliminated by diseconomies of scale due to increased bureaucracy and confusion (Hayes and Wheelwright, 1984). Unfortunately the academic research in the area of plant size decisions is far from being complete, which makes it difficult to estimate an "optimal" plant size. However, the AC pushes the optimal size to comprise a higher output volume owing to increased simplicity, which makes less demands upon large organization structures, primarily at the middle management level.

\section{ACKNOWLEDGEMENT}

The research is supported by grants from the Swedish Foundation for Strategic Research and the Lars Erik Lundberg Foundation for Research and Education. We also greatly acknowledge Ericsson Radio Systems AB for making this research report possible.

\section{REFERENCES}

Boone, T., Johnsson, S. P., Sisk, M. and Whybark, D. C. (1996) "An analysis of research on international operations networks", International Journal of Production Economics, 46-47, 477-88. 
Davidson, W. H. and de la Torre, J. (1989) Managing the Global Corporation Case Studies in Strategy and Management, McGraw-Hill, Singapore.

Hayes, R. H. and Wheelwright, S. C. (1984) Restoring our Competitive Edge Competing Through Manufacturing, John Wiley \& Sons, New York.

Hamel, G. and Prahalad, C. K. (1985) "Do you really have a global strategy?", Harvard Business Review, 63 (4) 139-48.

Hill, T. (1995) Manufacturing Strategy - Text and Cases, MacMillan, London.

Miltenburg, J. (1995) Manufacturing Strategy - How to Formulate and Implement a Winning Plan, Productivity Press, Portland.

Ohmae, K. (1985) Triad Power: The Coming Shape of Global Competition, The Free Press, New York.

Porter, M. E. (1986) "Competition in Global Industries" in Competition in Global Industries, (ed. M. E. Porter), Harvard Business School Press, Boston.

Rudberg, M., West, M. and Olhager, J. (1998) “A Model Factory Concept for Global Manufacturing - Flexibility through Standardization", Paper presented at the PCMM's $5^{\text {th }}$ International Conference on Manufacturing, Brisbane, Australia.

Rugman, A. M. and Verbeke, A. (1990) Global Corporate Strategy and Trade Policy, Routledge, London.

Sethi, A. K. and Sethi, S. P. (1990) "Flexibility in Manufacturing: A Review", International Journal of Flexible Manufacturing Systems, 2, 289-328.

Vollmann, T. E., Berry, W. L. and Whybark, D. C. (1997) Manufacturing Planning and Control Systems, $4^{\text {th }}$ ed., Irwin/McGraw-Hill, New York.

\section{BIOGRAPHY}

Martin Rudberg is a Ph.D. candidate at the Department of Production Economics and the International Graduate School of Management and Industrial Engineering, Linköping Institute of Technology. His research area is the interface between manufacturing strategy and MPC systems in global manufacturing.

Martin West is a Ph.D. candidate at the Department of Production Economics and the International Graduate School of Management and Industrial Engineering, Linköping Institute of Technology. His research focuses on productivity and flexibility in global manufacturing networks.

Jan Olhager is Associate Professor at the Department of Production Economics, Linköping Institute of Technology. He received a Master of Engineering from University of California at Berkeley and a Ph.D. from Linköping Institute of Technology. He has authored a book on manufacturing planning and control. He has published in international journals such as European Journal of Operational Research, International Journal of Operations and Production Management, International Journal of Production Economics, International Journal of Production Research, and Production Planning \& Control. His research interests include manufacturing strategy, MPC, flexibility, and modeling and analysis of production management systems. 